\section{Os dez mandamentos da observação participante}

William Foote WHYTE. Sociedade de esquina: a estrutura social de uma área urbana pobre $e$ degradada. Tradução de Maria Lucia de Oliveira. Rio de Janeiro, Jorge Zahar, 2005. 390 páginas.

\section{Licia Valladares}

Enfim o leitor brasileiro tem acesso a Street corner society de William Foote Whyte, um clássico dos estudos urbanos, obrigatório em todo curso de métodos qualitativos e pesquisa social. Gilberto Velho, autor da apresentação e responsável pela coleção "Antropologia Social" da Jorge Zahar, tomou a iniciativa de fazer traduzir a edição de 1993, comemorativa dos cinqüenta anos da primeira publicação do livro. A primorosa tradução inclui anexos que o próprio autor foi acrescentando nas várias reedições do livro, referentes à prática do trabalho de campo, ao depoimento de um dos personagens e à sua lista de publicações. Além de um índice remissivo, peça rara entre as publicações brasileiras, mas de uso fundamental quando se quer realizar uma leitura compreensiva de uma obra.

Originalmente publicado em 1943, o texto é não apenas atual pela temática que aborda - a juventude, a organização social das gangs e dos bairros pobres -, mas também um livro fundamental para aqueles que fazem trabalho de campo nas cidades, realizando o que os norte-americanos denominam anthropology at home. É também de grande importância para os sociólogos urbanos que cada dia aderem mais aos métodos qualitativos e aos estudos de caso e se interessam pelo tema das redes sociais, da juventude, da política local e da territorialização da pobreza. O subtítulo - A estrutura social de uma área urbana pobre e degradada - chama a atenção para a importância atribuída pelo autor aos temas da estrutura e da mobilidade social, normalmente considerados temáticas próprias da sociologia.

William Foote Whyte, filho de classe média alta norte-americana, pesquisou nos anos de 1930 uma área pobre e degradada da cidade de Boston, onde morava. Conhecido como um dos slums mais perigosos da cidade e sobre o qual circulavam várias idéias preconcebidas e estigmatizantes, o bairro italiano é pouco a pouco "desbravado" pelo aprendiz de pesquisador que apenas o conhecia por "ouvir dizer". Ao mesmo tempo em que se insere na localidade e vai redefinindo os objetivos de sua pesquisa, dá tropeços no convívio com os moradores, aprendendo a pensar e a refletir sobre a natureza de suas relações com os informantes. Aos poucos vai sendo aceito, muda-se inclusive para Cornerville, mas se dá conta de que é fundamental poder contar com um intermediário para realizar sua observação. "Doc", termo que define um informante-chave, simboliza esse mediador, que garante o bom acesso à localidade e/ou ao grupo social em estudo. Desempenha também o papel de conselheiro e "protetor", defendendo o pesquisador contra as intempéries e os imponderáveis próprios ao trabalho de campo. Após três anos de convívio e familiaridade com os diferentes grupos informais e instituições que atuavam e estruturavam a área (clubes sociais, centro comunitário, organizações informais etc.), Foote Whyte deixou o bairro para dedicar-se à difícil tarefa de redigir sua obra. Saída difícil e dolorosa para o observador participante, mas facilitada pelo fato de o jovem pesquisador mudar-se para Chicago, onde se inscreve como aluno de doutorado na universidade onde Robert Park havia bem marcado sua passagem.

Para além do interesse temático, este livro constitui um verdadeiro guia da observação participante em sociedades complexas. Minha opção será a de insistir na contribuição metodológica do autor, tendo em vista a verdadeira "moda" no Brasil de estudos de caso em "comunidades carentes" ou em territórios urbanos demarcados social e geograficamente.

Dez "mandamentos" podem ser depreendidos da leitura do livro:

1) A observação participante, implica, necessariamente, um processo longo. Muitas vezes o pesquisador passa inúmeros meses para "negociar" sua entrada na área. Uma fase exploratória é, assim, essencial para o desenrolar ulterior da pesquisa. O tempo é também um pré-requisito para os estudos que envolvem o comportamento e a ação de grupos: para se compreender a evolução 
do comportamento de pessoas e de grupos é necessário observá-los por um longo período e não num único momento (p. 320).

2) O pesquisador não sabe de antemão onde está "aterrissando", caindo geralmente de "pára-quedas" no território a ser pesquisado. Não é esperado pelo grupo, desconhecendo muitas vezes as teias de relações que marcam a hierarquia de poder e a estrutura social local. Equivoca-se ao pressupor que dispõe do controle da situação.

3) A observação participante supõe a interação pesquisador/pesquisado. As informações que obtém, as respostas que são dadas às suas indagações, dependerão, ao final das contas, do seu comportamento e das relações que desenvolve com o grupo estudado. Uma auto-análise faz-se, portanto, necessária e convém ser inserida na própria história da pesquisa. A presença do pesquisador tem que ser justificada (p. 301) e sua transformação em "nativo" não se verificará, ou seja, por mais que se pense inserido, sobre ele paira sempre a "curiosidade" quando não a desconfiança.

4) Por isso mesmo o pesquisador deve mostrar-se diferente do grupo pesquisado. Seu papel de pessoa de fora terá que ser afirmado e reafirmado. Não deve enganar os outros, nem a si próprio. "Aprendi que as pessoas não esperavam que eu fosse igual a elas. Na realidade estavam interessadas em mim e satisfeitas comigo porque viam que eu era diferente. Abandonei, portanto, meus esforços de imersão total" (p. 304).

5) Uma observação participante não se faz sem um "Doc", intermediário que "abre as portas" e dissipa as dúvidas junto às pessoas da localidade. Com o tempo, de informante-chave, passa a colaborador da pesquisa: é com ele que o pesquisador esclarece algumas das incertezas que permanecerão ao longo da investigação. Pode mesmo chegar a influir nas interpretações do pesquisador, desempenhando, além de mediador, a função de "assistente informal".

6) O pesquisador quase sempre desconhece sua própria imagem junto ao grupo pesquisado. Seus passos durante o trabalho de campo são conhecidos e muitas vezes controlados por membros da população local. O pesquisador é um observador que está sendo todo o tempo observado.
7) A observação participante implica saber ouvir, escutar, ver, fazer uso de todos os sentidos. É preciso aprender quando perguntar e quando não perguntar, assim como que perguntas fazer na hora certa (p. 303). As entrevistas formais são muitas vezes desnecessárias (p. 304), devendo a coleta de informações não se restringir a isso. Com o tempo os dados podem vir ao pesquisador sem que ele faça qualquer esforço para obtê-los.

8) Desenvolver uma rotina de trabalho é fundamental. O pesquisador não deve recuar em face de um cotidiano que muitas vezes se mostra repetitivo e de dedicação intensa. Mediante notas e manutenção do diário de campo (field notes), o pesquisador se autodisciplina a observar e anotar sistematicamente. Sua presença constante contribui, por sua vez, para gerar confiança na população estudada.

9) $O$ pesquisador aprende com os erros que comete durante o trabalho de campo e deve tirar proveito deles, na medida em que os passos em falso fazem parte do aprendizado da pesquisa. Deve, assim, refletir sobre o porquê de uma recusa, o porquê de um desacerto, o porquê de um silêncio.

10) O pesquisador é, em geral, "cobrado", sendo esperada uma "devolução" dos resultados do seu trabalho. "Para que serve esta pesquisa?" "Que benefícios ela trará para o grupo ou para mim?" Mas só uns poucos consultam e se servem do resultado final da observação. O que fica são as relações de amizade pessoal desenvolvidas ao longo do trabalho de campo.

Outros "mandamentos metodológicos" poderiam ser inferidos. Gostaria apenas de insistir sobre dois pontos. Da leitura do livro, fica claro que a observação participante não é uma prática simples mas repleta de dilemas teóricos e práticos que cabe ao pesquisador gerenciar. A experiência descrita e analisada pelo autor, numa linguagem que dispensa o jargão especializado, mostra que a observação participante exige, sim, uma cultura metodológica e teórica. Foote Whyte não vinha de uma formação em antropologia ou sociologia, mas havia estudado na tradicional e bem cotada Universidade de Harvard. Havia lido Malinowsky, Durkheim, Pareto, os Lynd 
(Middletown) e a literatura sobre communities. Teve contacto com Elton Mayo, que o orientou no aprendizado das técnicas de entrevista, e com o antropólogo Conrad Arensberg, com quem discutiu métodos de pesquisa de campo. Lloyd Warner, autor de Yankee city, veio a ser seu orientador na Universidade de Chicago. Para a revisão do manuscrito, contou com as sugestões de Everett Hugues. Como diz Gilberto Velho, na apresentação da edição brasileira, o livro "como produto final traz inevitavelmente as marcas de sua passagem e relações com alguns dos expoentes da Escola de Chicago dos anos 1940" (p. 12).

Outro aspecto importante diz respeito à atualidade do livro e sua pertinência para entender áreas pobres e o mundo popular no Brasil de hoje. O diagnóstico oferecido pelo autor contrapõe-se à imagem produzida pelo senso comum, que considera as áreas pobres exclusivamente um problema: degradadas, homogêneas, desorganizadas, caóticas e fora da lei, devendo necessariamente ser "ajudadas" uma vez que "abandonadas à sua própria sorte" nunca se desenvolverão. Vistas de dentro, e a partir do olhar arguto do cientista social, tem-se outra visão: tais localidades corresponderiam a áreas onde coexistem espaços e grupos locais diferenciados porém estruturados a partir de redes de relações sociais. A desorganização social não é, portanto, a tônica geral - o que não significa negar a existência do conflito entre os grupos. Foote White não tem, dessa forma, nem uma visão "miserabilista" nem populista dos pobres. O autor insiste na importância da sociabilidade que ocorre no espaço público do mundo popular, na "sociedade da esquina" para usar seu próprio linguajar. Pois é na esquina, no espaço informal, que as decisões são tomadas, que os grupos se estruturam e que as relações sociais se constroem e se destroem.

Que este livro sirva de "aviso" e inspiração a todos aqueles que queiram se lançar na aventura da observação participante.

\section{LICIA VALLADARES é professora de Sociologia da Universidade de Lille 1 e membro do Laboratório Clerse/CNRS. No Brasil é pesquisadora associada do Iuperj.}

\section{Pistas da sociologia para um século atormentado}

Robert BRYM, John LIE, Cynthia Lins HAMLIN, Remo MUTZENBERG, Eliane Veras SOARES \& Heraldo SOUTO MAIOR. Sociologia: sua bússola para um novo mundo. São Paulo, Thomson, 2006. 609 páginas.

\section{Ricardo Antunes}

Recentemente, o Conselho Nacional de Educação aprovou a volta do ensino de sociologia e filosofia para o ensino médio no Brasil. A decisão, auspiciosa, poderá possibilitar, em breve tempo, um estudo mais humanista e crítico que, de certo modo, contrasta com a razão instrumental que preside a sociabilidade contemporânea, na qual as chamadas "regras do mercado" têm tido cada vez mais prevalência, inclusive no âmbito educacional. Teremos, então, uma real retomada dos estudos de sociologia e filosofia em nossas escolas. O que nos obriga, nas universidades, a formar melhores sociólogos e filósofos.

Se já temos aqui publicado várias obras de muitos dos autores clássicos das ciências sociais, com boas edições e mesmo traduções, se já podemos consultar o denso Dicionário do pensamento social do século $X X$ (organizado por William Outhwaite, Tom Bottomore et al., publicado pela Jorge Zahar Editor), agora, em boa hora, podemos saudar este novo livro que acaba de ser publicado no Brasil. Sociologia: sua bússola para um novo mundo é um empreendimento intelectual de fôlego: em suas mais de seiscentas páginas, oferece um panorama abrangente, complexo e heterogêneo das incontáveis questões, desafios, dilemas e problemas nestes conturbados séculos, o XX que já se foi e o XXI que acaba de principiar.

Desde logo seus autores mostram que o projeto do livro, entretanto, tem claro contraste com as enciclopédias. Se estas ensinam o que pensar sobre tantos temas, este novo livro pretende demonstrar como os sociólogos formulam suas questões e indagações e, desse modo, possibilitar que as respostas sejam encontradas pelos leitores/as.

Embora seu desenho apresente a formatação de algum modo aparentada com as enciclopédias 